\title{
Notícias da Rem
}

\section{Usiminas aumenta participação no mercado interno}

\begin{abstract}
Empresa deverá encerrar 2002 com participação de $38 \%$ no mercado brasileiro, refor-
\end{abstract} çando compromisso com abastecimento interno

O Sistema Usiminas (integrado pela Cosipa) comercializou, em novembro, 717,9 mil toneladas de laminados planos. Desse total, 474,7 mil toneladas foram vendidas no mercado interno e 243,2 mil, no mercado externo.

$\mathrm{O}$ volume comercializado no mercado interno, em novembro, é o segundo maior do ano, ficando abaixo apenas do recorde de outubro, de 496,8 mil toneladas. Esse volume consolida, mais uma vez, o compromisso da Usiminas com o abastecimento do mercado interno, já definido como prioritário pela siderúrgica.

A perspectiva de participação da Usiminas (excluindo Cosipa) no mercado interno, em 2002, é de $38 \%$ - percentual superior ao verificado nos últimos anos. Essa participação cresceu significativamente ao longo do segundo semestre deste ano: saltou de $36,2 \%$ nos seis primeiros meses de 2002 para os cerca de $40 \%$ com os quais a siderúrgica deverá fechar o segundo semestre - o que, mais uma vez, demonstra a importância do mercado interno para a empresa.

\section{Estimativa}

Até novembro, a Usiminas comercializou 3,7 milhões de toneladas. Desse total, 2,9 milhões foram destinadas ao mercado interno e 821 mil toneladas ao mercado externo. A estimativa para o fechamento do ano é de um volume de comercialização de 4,1 milhões de tone-

ladas, sendo 3,2 milhões no mercado interno e 905 mil toneladas no exterior.

Na Cosipa, o volume comercializado, até novembro, atingiu 3,1 milhões de toneladas, sendo 1,9 milhão no mercado interno e 1,2 milhão no mercado externo. As estimativas para o ano apontam para um volume de 2,1 milhões de toneladas no mercado interno e de 1,4 milhão de toneladas no exterior, perfazendo um total geral de 3,5 milhões de toneladas de produtos comercializados.

A Cosipa deverá encerrar o ano com uma participação de $24,6 \%$ no mercado interno. No primeiro semestre, essa participação foi de $23,8 \%$. No segundo semestre, deverá fechar em $25 \%$.

Como resultado, o Sistema Usiminas deverá encerrar 2002 com uma participação média de $62,6 \%$ na demanda de laminados planos - um número superior à média dos últimos anos.

\section{Unigal}

O desempenho da Unigal, joint venture entre Usiminas e Nippon Steel, que produz galvanizados por imersão a quente - HDG -, também continua surpreendendo. A empresa comercializou 35,9 mil toneladas de produtos em novembro - recorde histórico da empresa das quais 24,5 mil no mercado interno e 11,4 mil no mercado externo. O ritmo de produção repetiu o de outubro, atingindo 34,3 mil toneladas.

\section{6 - 2002}

Não esconda seu trabalho. Publique-o na REM

66 anos divulgando ciência.

\section{Usiminas investe em novos produtos e serviços para a construção civil}

A Usiminas, maior produtora de aços planos do Brasil, tem investido intensamente no desenvolvimento de produtos e serviços para alavancar a construção metálica. Para isso, lançou, esse ano, novos aços e colocou em prática uma política comercial voltada para o atendimento específico do setor de construção civil. As estratégias de comercialização, além dos produtos desenvolvidos para atender esse mercado, foram mostradas pela empresa durante o II Congresso Internacional da Construção Metálica (II CICOM) e durante a Feira Construaço, que aconteceram, paralelamente, de 11 a 13 de novembro no Frei Caneca Shopping Center \& Convention Center, em São Paulo (SP).

A política comercial implantada pela Usiminas levou à criação de uma gerência de vendas de construção civil para atuar em conjunto com a gerência de desenvolvimento da aplicação do aço, existente há 20 anos, na busca do desenvolvimento técnico de produtos associados à venda do aço e desenvolvimento dos negócios dos clientes. Esse assunto foi tema da palestra "Diretrizes estratégicas de comercialização da Usiminas - o foco na construção civil" dentro do painel sobre o mercado do aço na construção civil do II CICOM.

$\mathrm{Na}$ Construaço, os produtos e tecnologias da siderúrgica mineira poderão ser vistos no estande do Grupo Siderúrgico da Construção Metálica, que reúne cinco siderúrgicas brasileiras. A Usiminas apresentará suas tecnologias e produtos, como a nova geração de aços para construção civil, uma evolução no atendimento às necessidades do setor e o Usiteto, um programa habitacional desenvolvido pela empresa para a construção de moradias em larga escala. 


\section{Aumento do aço leva governo a liberar licenças automáticas de importação}

O governo autorizou as importações de aço e algodão a voltarem ao sistema de licenciamento automático, o que poderá reduzir de 60 dias para dez 10 dias o processo de entrada desses produtos no país. A medida foi anunciada pela secretária de Comércio Exterior do Ministério do Desenvolvimento, Lytha Spindola, por meio de um comunicado. No caso do aço, foi uma reivindicação de 12 sindicatos que representam grandes consumidores de aço, entre eles a Anfavea (montadoras), o Sindipeças (autopeças) e o Sindiforja.

Dos 200 produtos siderúrgicos que passavam por uma avaliação prévia na importação, apenas dez continuarão no antigo sistema. O algodão passará a ser liberado automaticamente. O presidente da Anfavea, Ricardo Carvalho, disse que o pedido foi feito porque as montadoras não estão agüentando a pressão dos custos e não tem conseguido repassá-los integralmente para os preços. $\mathrm{O}$ aço representa de 55\% a $60 \%$ da composição de um carro.

Segundo Carvalho, o preço aço subiu $40 \%$ desde o começo do ano e as siderúrgicas querem impor um novo aumento de $17 \%$ em dezembro. Ele disse que a prioridade dada pelas siderúrgicas às exportações tem provocado desabastecimento. Os sindicatos também estariam preocupados com uma suposta tentativa de "dolarização" do produto, disse. A produção siderúrgica tem custos em moeda estrangeira, como o carvão e o aço, os quais têm preços referenciados no exterior.

O presidente da Anfavea afirmou que o fim do monitoramento não significara um aumento das importações por parte das montadoras. $\mathrm{O}$ aço nacional ainda é mais barato. Carvalho não explicou por que então o monitoramento beneficia a indústria automotiva. Aparentemente, as montadoras querem se precaver caso haja um desabastecimento maior.

A medida impõe uma derrota às siderúrgicas brasileiras. O monitoramento foi adotado a pedido dessas empresas em resposta as salvaguardas impostas pelos EUA e pela Europa. A CSN acaba de fazer um reajuste de $10 \%$ no preço do aço no mercado interno para vigorar esse mês. No ano, a siderúrgica já acumula $50 \%$ de reajuste do produto. A informação é de Antonio Ulrich, diretor do Centro Corporativo e de Relações com Investidores da companhia.

Ele atribuiu o aumento do preço do aço à desvalorização cambial. "Aumentamos o produto no mercado interno por causa do dólar", explicou. A CSN deve produzir, em 2002, 5 milhões de toneladas de aço e fechar o ano colocando $65 \%$ de sua produção no mercado doméstico e exportando $35 \%$. Normalmente, a siderúrgica exporta $25 \%$ de sua produção. Ulrich nega que o mercado doméstico de aço esteja desabastecido. (Valor, 06/12 e www.infomet.com.br).

\section{Samarco: Imposto Solidário}

A Samarco entregou, em dezembro, o repasse de $\mathrm{R} \$ 20.394,98$ para os Conselhos Municipais dos Direitos da Criança e do Adolescente de Ouro Preto e Mariana. A Fundação Projeto Sorria, o Centro Educacional Antônio Pereira, a Casa Lar Estrela e o Centro de Integração Familiar foram as entidades escolhidas pelos empregados para serem beneficiadas pelo Imposto Solidário. A empresa assinou um convênio com os Conselhos Municipais dos Direitos da Criança e do Adolescente das duas cidades, que, por sua vez, vão repassar o valor para as instituições até fevereiro de 2003.

O Programa Imposto Solidário foi criado pela Samarco em 2000 para estimular os seus empregados, familiares e amigos a destinarem até $6 \%$ do Imposto de Renda devido para entidades beneficentes cadastradas nos fundos de amparo a crianças e adolescentes nos municípios de Anchieta, Guarapari, Belo Horizonte, Mariana e Ouro Preto.

\section{Sistema Usiminas bate recorde de comercialização no mercado interno}

\author{
Mercado nacional recebeu meio milhão de \\ toneladas de aço
}

Em outubro, mês em que comemorou 40 anos de operação, o Sistema Usiminas (Usiminas e Cosipa) registrou recorde anual de comercialização de laminados planos no mercado interno. Foram 496,8 mil toneladas de produtos (praticamente meio milhão de toneladas) vendidas no mercado brasileiro, melhor resultado obtido até agora em 2002.

Ao todo, o Sistema Usiminas comercializou, em outubro, 762,5 mil toneladas de laminados planos. Desse total, 496,8 mil toneladas foram comercializadas no mercado interno e 265,7 mil toneladas no mercado externo.

O volume de laminados planos comercializados no mercado interno é $10,8 \%$ superior à média mensal de 2001 e $14 \%$ maior que o volume médio mensal de 2002 - o que comprova o comprometimento da Usiminas com o mercado nacional.

O setor automotivo (indústria automobilística e autopeças) continua sendo um dos principais consumidores de laminados. O Sistema Usiminas destinou a esse setor, em outubro, 74,5 mil toneladas, mantendo a média histórica destinada à indústria automotiva.

Somente a Usiminas comercializou, em outubro, 370 mil toneladas de laminados planos, das quais 303 mil no mercado interno e 67 mil toneladas no mercado externo. Já a Cosipa vendeu 393 mil toneladas de laminados planos. Deste total, 194 mil foram destinadas ao mercado interno e 199 mil ao mercado externo.

O Sistema Usiminas também comemorou, em outubro, mais um recorde. A Unigal, a joint venture entre Usiminas e Nippon Steel, que produz aço galvanizado por imersão a quente - HDG, comercializou, em outubro, 30 mil toneladas, o que significa que a empresa já está operando em ritmo de plena carga. Desse total, 21,5 mil toneladas foram vendidas no mercado interno.

Até julho deste ano, a Unigal, inaugurada em 2000, vinha operando com uma média mensal de vendas de 19 mil toneladas. $\mathrm{O}$ aço eletrogalvanizado por imersão a quente produzido pela Unigal é um produto nobre, destinado principalmente aos setores da indústria automobilística, construção civil e linha branca (eletrodomésticos). 


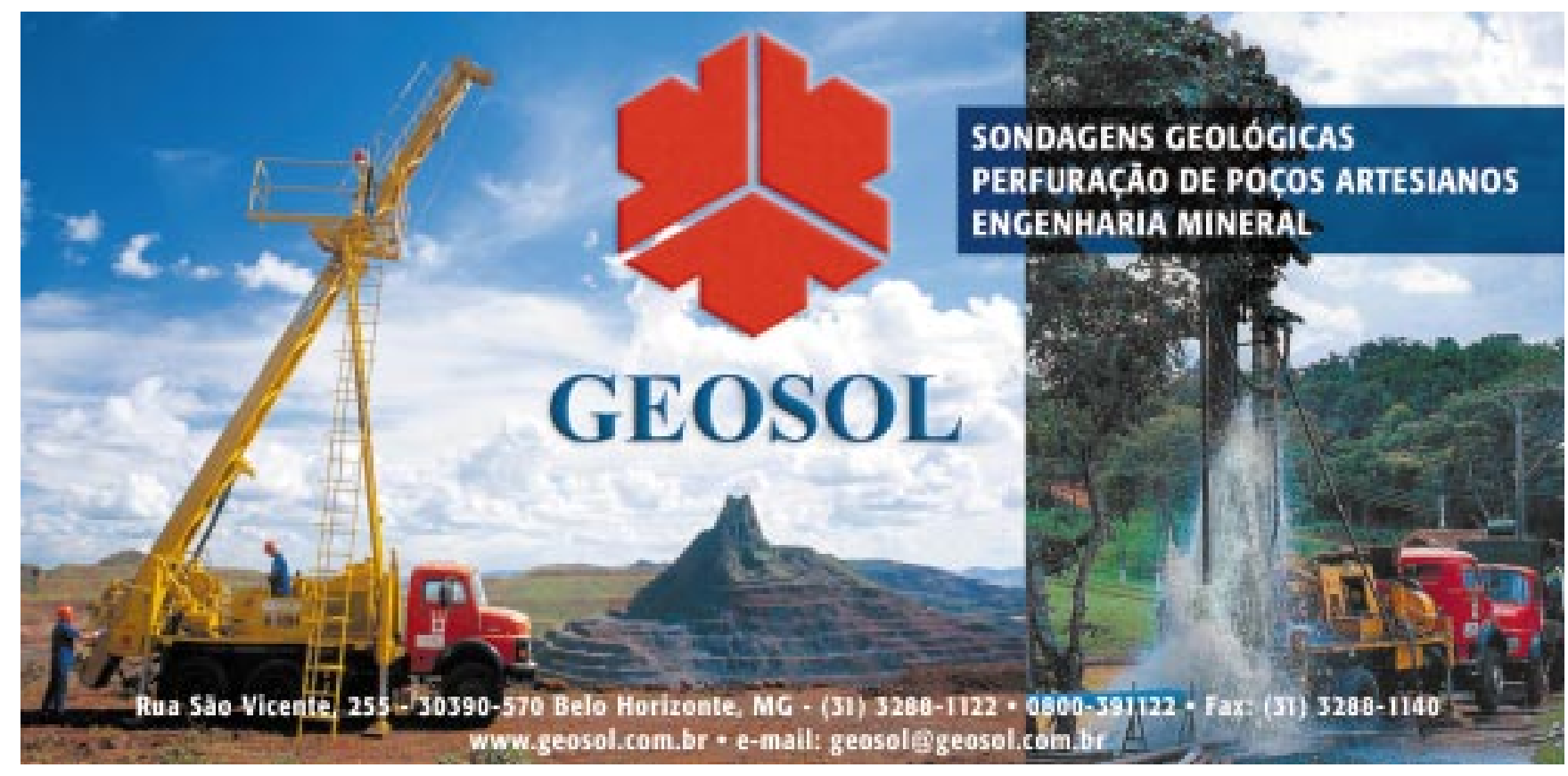

\section{Pneus Caterpillar agora no Brasil}

A Caterpillar está lançando no Brasil sua linha de pneus, rodas e conjuntos montados para minicarregadeiras e para manipuladores telescópicos. Seu objetivo é ampliar a produtividade de seus equipamentos nas mais diversas aplicações e reduzir custos de manutenção para seus clientes. Composta de seis modelos, com várias medidas, a linha de pneus é resultado de uma pesquisa ampla entre usuários de máquinas e do conhecimento tecnológico acumulado ao longo de seus 77 anos de produção mundial de equipamentos. Umas das novidades dessa nova linha é o pneu de perfil baixo (Low Side Wall). O uso desse modelo permite operar a máquina com o pneu furado, sem danificá-lo, evitando interromper o trabalho para troca do pneu durante a jornada.

A nova linha conta, ainda, com pneus de alta flutuação, projetados para trabalhos em terrenos macios que substituem o uso de esteira na maioria das aplicações. Há, ainda, a opção de duas versões de modelos sólidos, um para superfícies aprimoradas e outro flexível, indicado para superfícies irregulares. Completa a nova linha, o pneu Extremo Pesado ? XD, com vida útil $30 \%$ superior em aplicações severas como trabalhos em pedreiras e fábricas de concreto.

Os Pneus Caterpillar também podem ser adquiridos como conjuntos montados (pneus e rodas) prontos para uso. Essa opção possibilita instalação mais rápida, além de ser uma vantagem adicional nos reparos de emergência no campo. Além da conveniência e rapidez, os conjuntos montados são projetados para oferecer encaixes herméticos e perfeitos, assegurando que nenhum flange empene, além de evitar o alargamento dos furos dos parafusos ou a deformação dos furos-pilotos.

\section{Prevenção total contra furos}

Os conjuntos montados também podem ser adquiridos com enchimento de poliuretano. Essa novidade fornece prevenção total contra pneu furado, eliminando praticamente os custos de reparo. Proporciona, ainda, vantagens importantes, tais como: maior vida útil , maximização das horas de serviço do pneu, possibilidade de várias recauchutagens, au- mento da absorção de choque, distribuição uniforme a carga em toda a carcaça do pneu. Este é um diferencial importante, uma vez que o custo de pneus furados é realmente alto. Com essa opção, além de reduzir despesas com reparos e substituição dos pneus, evita-se a de interrupção do trabalho de outros equipamentos, garantindo a produtividade da máquina e da operação como um todo.

É importante destacar que os conjuntos atendem às especificações do fabricante e que os novos pneus são compatíveis com diversos modelos concorrentes. Estão disponíveis na rede de revendedores Caterpillar, com cobertura nacional.

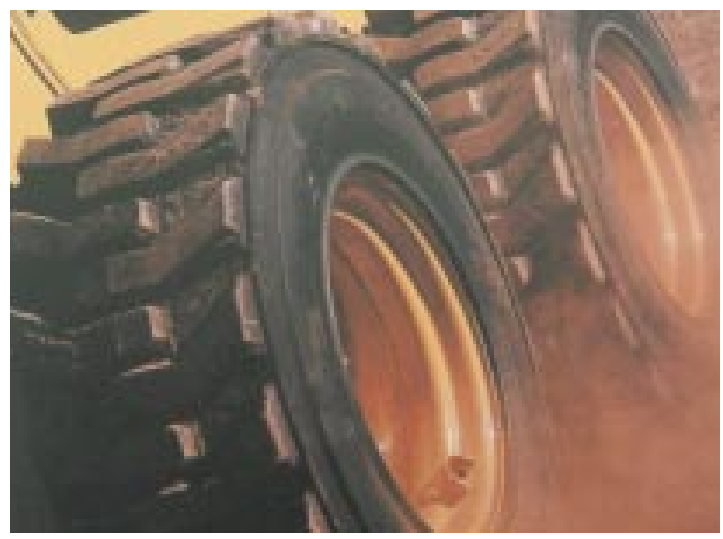




\section{OMC critica barreiras americanas ao aço mas aceita tese de subsídio para siderúrgicas}

Barreiras impostas pelos Estados Unidos a siderúrgicas privatizadas na Europa foram consideradas, pelo órgão de Apelação da Organização Mundial do Comércio (OMC), incompatíveis com as regras internacionais. A decisão do órgão da OMC confirma julgamento anterior feito por uma comissão de arbitragem e obriga o governo norte-americano a retirar as barreiras. Recomenda, ainda, que os Estados Unidos mudem as normas internas que as justificaram. Caso contrário, os Estados Unidos terão de dar compensações à União Européia, ou estarão sujeitos a retaliações comerciais.

Um aspecto na decisão da $\mathrm{OMC}$, no entanto, impede a Europa e paises interessados no assunto, como o Brasil, de comemorarem a derrota da medida protecionista norte-americana: o órgão de apelação, embora tenha conden ado as barreiras, rejeitou o argumento europeu de que a privatização das estatais, com mecanismos e preços de mercado, extingue automaticamente os subsídios concedidos na época do controle estatal. Esse argumento também é usado pelo Brasil nas controvérsias com os EUA em relação às medidas adotadas pelos americanos contra supostos subsídios ao aço.

A decisão final da OMC significa que não bastará, para os países afetados pelas barreiras, demonstrar que a privatização respeitou os mecanismos e preços do mercado e, com isso, eliminou qualquer vantagem obtida pelas siderúrgicas em seu tempo de estatal. A decisão altera o veredicto anterior do comitê de arbitragem (painel, na terminologia da OMC) que julgou o caso. O painel havia decidido, em agosto, que a legislação interna dos EUA estaria em desacordo com as regras da OMC, por não levar em conta que a privatização, em condições e a preços de mercado, daria fim aos subsídios recebidos por siderúrgicas estatais.

“A privatização, em condições e a preços justos de mercado, geralmente extingue qualquer beneficio remanescen- te gerado por alguma contribuição financeira isolada recebida anteriormente", concluiu o órgão de Apelação da OMC. "Mas discordamos do painel de que esse resultado ocorrerá necessariamente e sempre que a privatização ocorrer em condições e preços de mercado".

Os EUA terão, porém, de provar que, apos a venda da siderúrgica ao setor privado, o comprador continuou beneficiando-se com subsídios que as estatais tenham recebido do governo do país exportador. Segundo o órgão de apelação da OMC, os Estados Unidos não conseguiram provar essa vantagem desleal em 12 casos nos quais produtos siderúrgicos de empresas como a Corus e a Arcelor foram afetados pelas barreiras, cotas e tarifas chamadas de "medidas compensatórias" no jargão do comércio internacional.

O país com mais produtos afetados pelas medidas norte-americanas condenadas pela OMC é a Itália (cinco). A Franca teve três produtos beneficiados pela decisão da OMC e a Suécia, a Alemanha, a Inglaterra e a Espanha, um tipo de produto siderúrgico cada.

A decisão da OMC surpreendeu as autoridades brasileiras, que ainda avaliam se a medida traz mais vantagens ou desvantagens para o país. Segundo um especialista, à primeira vista o veredicto do órgão de apelação pode tornar-se o tipo de decisão na OMC que permite os dois lados saírem cantando vitória. A OMC tem sido criticada duramente no Congresso americano pelo grande número de decisões contra a defesa comercial dos EUA.

Em demonstração da complexidade da decisão da OMC, agências de notícias americanas divulgavam o resultado como uma derrota da Europa, por derrubar o argumento de que os subsídios estariam automaticamente eliminados com as privatizações. (Valor, 10/12 e www.infomet.com.br).

\section{Eleita a nova diretoria da APG-RJ}

Sessenta colegas participaram do processo eleitoral para a escolha da nova Diretoria da APG-RJ (Associação Profissional dos Geólogos do Estado do Rio de Janeiro), no biênio 2003/2004. Com 59 votos válidos foi eleita a Chapa "Novos tempos, novos desafios", com a seguinte composição: Presidente - Ricardo Latgé Milward de Azevedo (PETROBRAS); Vice-Presidente - Benedicto Humberto Rodrigues Francisco (Museu Nacional); Secretário - Rita Redaelli (Autônoma); Tesoureiro - Cássio Roberto da Silva (CPRM); Diretoria Suplente - Egberto Pereira (UERJ), José Alberto Bucheb (PETROBRAS) e Jorge Eduardo Pinto Hausen (CPRM); Conselho Fiscal - Marcelo Cavalcante Berbert (Autônomo), Antonio Ivo de Menezes Medina (CPRM) e Walter Rubens Hildebrand (Autônomo).

A Diretoria agradece aos colegas que participaram do processo e espera poder ampliar ainda mais a intervenção dos associados na condução e fortalecimento da Entidade.

\section{Em janeiro a REM}

completará 67 anos.

Venha comemorar conosco mais uma marca dessa que é a mais antiga revista técnica do setor mínero-metalúrgico

da América do Sul. Anuncie Publique e

Assine a

REM 


\section{Programa da Samarco de Educação Ambiental ganha prêmio internacional}

O Programa da Samarco de Educação Ambiental de Bento Rodrigues ganhou o prêmio internacional Saúde e Segurança em Meio Ambiente e Comunidade (HSEC - Health, Safety, Environment and Community) da BHP Billiton, que divide o controle da mineradora com a Companhia Vale do Rio Doce (CVRD). O prêmio no valor de US\$ 2.500 foi entregue, no dia 11 de dezembro, à Associação de Hortifrutigranjeiros de Bento Rodrigues (Ahobero).

A cerimônia aconteceu na Associação dos Moradores da comunidade com a presença de representantes da Samarco, da prefeitura de Mariana e da comunidade local. O dinheiro recebido será usado para a conclusão das obras de construção do galpão da Ahobero que está investindo na agroindústria e gerando novas fontes de renda para o povoado.

O reconhecimento da BHP Billiton ao Programa de Educação Ambiental de Bento Rodrigues patrocinado pela Samarco veio coroar a importância deste tipo de iniciativa singular que tem como objetivo promover o desenvolvimento cultural e socioeconômico da comunidade local. Em 1997, os cerca de 500 habitantes de Bento Rodrigues conviviam com a degradação ambiental, com a pobreza, com a baixa escolaridade e com a falta de oportunidades profissionais para os moradores, algo comum a grande parte dos municípios brasileiros.

Com a implantação do Programa há cinco anos, houve uma melhoria considerável da qualidade de vida dessa comunidade. Os resultados atingidos foram a redução no número de repetências entre os alunos de $1^{\mathrm{a}}$ a $4^{\mathrm{a}}$ séries (de $30 \%$ para $5 \%$ ) e de evasão escolar (de $30 \%$ para menos de 10\%), diminuição da carência nutricional e queda de $30 \%$ na incidência de verminoses, redução do número de queimadas na região (de oito para duas ocorrências/ano). Também foram criadas perspectivas de trabalho e geração de renda através da implantação de uma agroindústria local, coordenada pela Ahobero.

Esta melhora na condição de vida dos moradores de Bento Rodrigues foi possível graças a atuação conjunta da Samarco e da população local. O projeto, que recebeu investimentos de US\$ 85 mil da mineradora, teve como base ações integradas capazes de fortalecer a comunidade para que ela construa, de forma autônoma, novas perspectivas para o desenvolvimento local.

O mais interessante do Programa de Educação Popular Ambiental Bento Rodrigues é que sua aplicação não exige equipamentos sofisticados ou tecnologia de ponta. $\mathrm{O}$ diferencial do projeto é investir em uma metodologia inovadora de mobilização para a ação comunitária autônoma, inspirada no conceito de Agenda 21 Local, e tem como princípio orientador a criação de condições para que a própria comunidade seja agente do seu desenvolvimento.

\section{ONDE TEM \\ QUALIDADE TEM \\ MINASLIGAS}

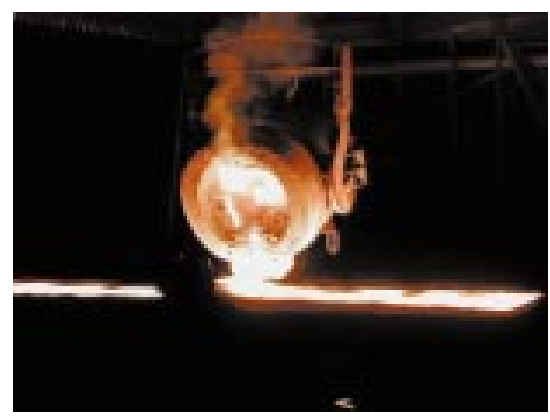

\section{FERRO SILÍCIO 75\%, SILÍCIO METÁLICOE MICROSÍLICA}

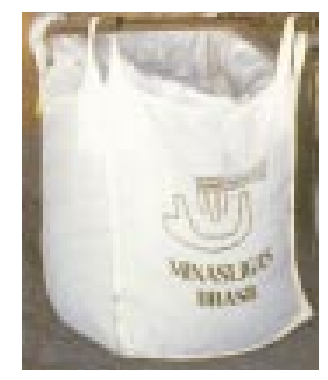

MINASLIGAS

\section{www.minasligas.com.br}
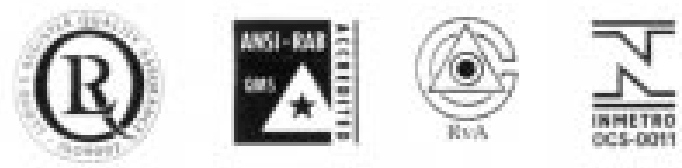

End. Comercial

Rua Paraíba 1122 4 e 5Andares

Funcionários Cep 30.130-141

Belo Horizonte/MG

Telefone: (31) 3261-8666

Fax: (31) 3261-8789

E mail: sales@minasligas.com.br 


\section{GEMCOM se lança no mercado de cobre brasileiro junto com a gigante CVRD}

A Gemcom Software Internacional Inc., uma empresa líder mundial nas áreas de tecnologia da informação, focada na indústria mineral em seus vários ramos de atividade, anunciou, no dia 26 de novembro, a assinatura de mais um contrato no valor de Can $\$ 167.000$ (Dólares Canadenses), entre a Gemcom do Brasil e a Companhia Vale do Rio Doce, para seu novo projeto de cobre em Carajás. O Projeto Sossego marcará o lançamento da CVRD no mercado de cobre.

Somando ao Gemcom, ao Whittle e às avançadas tecnologias terceirizadas, a Gemcom fornecerá também uma larga escala de serviços de suporte técnico.

O Projeto Sossego significa um grande passo rumo à expansão desse novo setor, disse Bek Nader, vice-presidente da Gemcom, Unidade de Negócio do Brasil. Com a mais avançada tecnologia para planejamento de mina, esse projeto é o primeiro de muitos a serem realizados dentro do mercado de cobre da CVRD. Crescendo a cada dia nesse território, a Gemcom está provando sua habilidade de fornecer soluções em grande escala e flexíveis a todas as operações da CVRD.

Márcio Godoy, Gerente Geral de Planejamento de Mina e Controle de Qualidade, da divisão de cobre da CVRD, disse que o "start-up" do Projeto Sossego será em meados de 2004, mas as plantas estão já no lugar ideal para que se possa dar início a diversos outros projetos de cobre, esperando uma produção da ordem de 700.000 toneladas até 2007. Disse também que, com o objetivo de tornar cada vez mais eficiente os processos da mina, a Gemcom foi nomeada como o primeiro fornecedor de avançadas tecnologias para todas as futuras atividades geológicas e de planejamento de mina da CVRD.

Esse contrato foi realizado logo a seguir a um outro acordo recentemente anunciado entre a Gemcom e a CVRD, através do qual a Gemcom estará fornecendo o equivalente a Can $\$ 150.000$ (Dólares Canadenses) em Softwares e serviços de tecnologia de informação voltados para mineração à CVRD na região de Carajás.

\section{Sobre a Gemcom}

A Gemcom é líder mundial por fornecer em grande escala soluções para planejamento e produção na indústria da mineração. Estabelecida em 1985, a companhia é uma fornecedora de primeira linha de aplicações técnicas para a área de mineração, serviços profissionais, treinamento e suporte. As informações confiáveis e fornecidas a tempo pelas Soluções Gemcom permitem um perfeito controle durante todo o ciclo de vida de uma mina, podendo reverter essas soluções em milhões de dólares em ganhos na produtividade.

As soluções Gemcom incluem o GEMS, um sistema que permite uma larga escala de aplicações técnicas e de controle de todos os aspectos que dizem respeito ao desenvolvimento de uma mina.

A Gemcom tem uma sólida base de clientes em mais de 75 países, abrangendo mais de 1000 minas, que incluem os gigantes da indústria da mineração, tais como CVRD, De Beers, Rio Tinto, Teck Cominco, Noranda, Codelco e Anglo American, que confiam plenamente no Software da Gemcom para facilitar tomadas de decisão econômica em suas operações.

A Gemcom Software International, da qual a Gemcom do Brasil é subsidiária, é uma empresa canadense com sede em Vancouver e escritórios em todos os principais centros de mineração do mundo, Canadá, Estados Unidos, Brasil, Chile, Peru, Inglaterra, Austrália, China, Índia e Africa do Sul, e agentes na Espanha e Irã.

Para mais informações, visite o Gemcom web site no endereço www.gemcomsoftware.com.

\section{APG-RJ cobra o funcionamento do GEPAC}

Em entrevista à Rede Globo, transmitida no Jornal RJ-TV que foi ao ar no dia 11/12/2002, o Presidente da APG-RJ defendeu a necessidade de funcionamento do Grupo de Executivo de Prevenção de Acidentes Naturais e Catástrofes (GEPAC) na formulação de uma política pública para reduzir os riscos dos recorrentes e trágicos deslizamentos de encostas e inundações que anualmente ceifam vidas de fluminenses e cariocas, como os que ocorreram no dia 8 passado em Angra dos Reis.

O GEPAC foi instituído no inicio de abril desse ano, por Decreto do Governador Antony Garotinho. A expectativa da sociedade era de que a equipe da Governadora Benedita da Silva valorizasse a ação deste grupo de trabalho, que integra secretarias e autarquias estaduais como universidades e entidades da sociedade civil, entre elas a APGRJ, sem ônus ao erário público. Apesar da pronta solicitação da Secretaria Estadual de Defesa Civil (SEDEC) para que os participantes indicassem seus representantes, as reuniões mensais exigidas pelo Decreto não ocorreram. Em outubro, a APG-RJ encaminhou carta à Governadora alertando para a inoperância do GEPAC, que, nesses meses, já poderia ter definido estratégias importantes para aparelhar e articular o Governo do Estado com as prefeituras objetivando a prevenção dos riscos desses acidentes.

Perante a tragédia de Angra dos Reis, resta-nos lamentar mais essa omissão do poder público estadual e reforçar os nossos argumentos com vistas a viabilizar no Governo a implementação do GEPAC. 